\title{
Screening of suitable tossa jute (Corchorus olitorius L.) mutant to increase fiber production
}

Md. Robiul Islam Akondo ${ }^{1}$, Md. Belal Hossain ${ }^{2,}{ }^{*}$, Md. Sefaur Rahman ${ }^{1}$, Md. Shamiul Haque ${ }^{3}$ and Md. Abul Kalam Azad 3

${ }^{1}$ Bangladesh Institute of Nuclear Agriculture (BINA) Sub-station, Gopinathpur, Gopalganj, Bangladesh.

${ }^{2}$ Soil Science Division, Bangladesh Institute of Nuclear Agriculture, BAU campus, Mymensingh, Bangladesh.

${ }^{3}$ Plant Breeding Division, Bangladesh Institute of Nuclear Agriculture, BAU campus, Mymensingh, Bangladesh.

Publication history: Received on 19 January 2020; revised on 07 February 2020; accepted on 11 February 2020

Article DOI: https://doi.org/10.30574/gscbps.2020.10.2.0014

\begin{abstract}
The present study was conducted at the research farm of Bangladesh Institute of Nuclear Agriculture (BINA) Substation, Gopalganj, to find out the effective mutant for increasing fiber production of jute during March - September 2019. Mutant lines (JRO-1000-8, JRO-1000-10, JRO-700-3, JRO-1000-9) and two check varieties (JRO-524, BJRI-8) were used in this study. The experimental design was a randomized completely block with three replications. Morphological characters, plant height and base diameter were studied for the screening of jute mutants for higher yield. Results indicated that the highest plant height $(3.26 \mathrm{~m})$ in JRO-524 and base diameter $(6.88 \mathrm{~cm})$ in JRO-1000-8 found in this study. On the other hand, the highest fiber and stick yields were found in JRO-1000-9 and JRO-524, respectively. JR0-1000-8 and JR0-1000-10 mutants produced higher stick yield than JR0-1000-9 mutant. BJRI-8 variety gave inferior results compared to all mutants and check variety JR0-524 except stick yield. The highest harvest index was observed in JRO-1000-9 and BJRI-8. JR0-1000-9 mutant produced 30.24\% fiber yield over BJRI-8 check variety. Positive and significant correlation was found between plant height and stick yield of jute. It may be concluded that JRO-1000-9 was found to be the best mutant for increasing fiber production of jute.
\end{abstract}

Keywords: Bangladesh; Jute mutants; Yield contributing characters; Fiber yield

\section{Introduction}

Jute (Corchorus spp.), the golden fiber of Bangladesh and the most important bast fiber of the world, is extracted from Corchorus olitorius L. grown extensively in India and Bangladesh. It is an important cash crop in Bangladesh and India, which together accounts for about $84 \%$ of the world production of jute fiber [1]. Besides, Bangladesh and India, it is also grown to some extent in China, Myanmar, and Nepal. Among jute growing countries in the world, Bangladesh ranks second in respect of jute production. Of the jute cultivated area, tossa, white and kenaf cover 85,8 and $7 \%$, respectively [2].

One of the important characteristics of jute is that it is free from health hazards and environmental pollution [3]. Jute is also versatile, durable, reusable, cheap, and superior to synthetic fiber. Other major advantages of jute are that it is agro-based, produced annually, renewable, and biodegradable [4]. Jute is considered as the best natural substitute for nylon and polypropylene. Jute is also recognized as a solution to produce eco-friendly products for the future. It improves soil productivity because it massive leaf dropping and root proliferation in the field. It has an increasing demand for the substitute materials of non-degradable synthetics. Now a day attempt is made to popularize the jute plants for making pulp in paper industries. Quality fiber containing jute variety is not available in Bangladesh.

\footnotetext{
${ }^{*}$ Corresponding author

E-mail address: belalbina@gmail.com
} 
Statistics show that the jute cultivation area has been declined gradually from 7.601 lac hectare in 2011-12 to 6.726 lac hectare in 2014-15 (Figure 1). Fiber production rate was from 2.80 t/ha 2006-07 to 2.68 t/ha 2014-15. Total fiber production was from $20.15 \times 10^{5}$ tons to $18.00 \times 10^{5}$ tons in 2014-15. On the other hand, jute production had reduced from 2.015 lac tons to 1.800 lac tons during the last five years [5]. It appears from the recent record that in Bangladesh, not only the area under jute is declining; the crop is pushed more and more to the marginal lands [6]. Jute cultivation area declines in Bangladesh due to the competition with rice, falling market demand and increase the use of synthetic bras. So, horizontal expansion of jute cultivation is not possible in Bangladesh. On the other hand, the limited number of jute varieties is available for increasing fiber production in Bangladesh. So, research is needed to develop improved tossa jute variety for increasing fiber production. Therefore, the present study was undertaken to find out the higher jute yield variety for the farmers of Bangladesh.

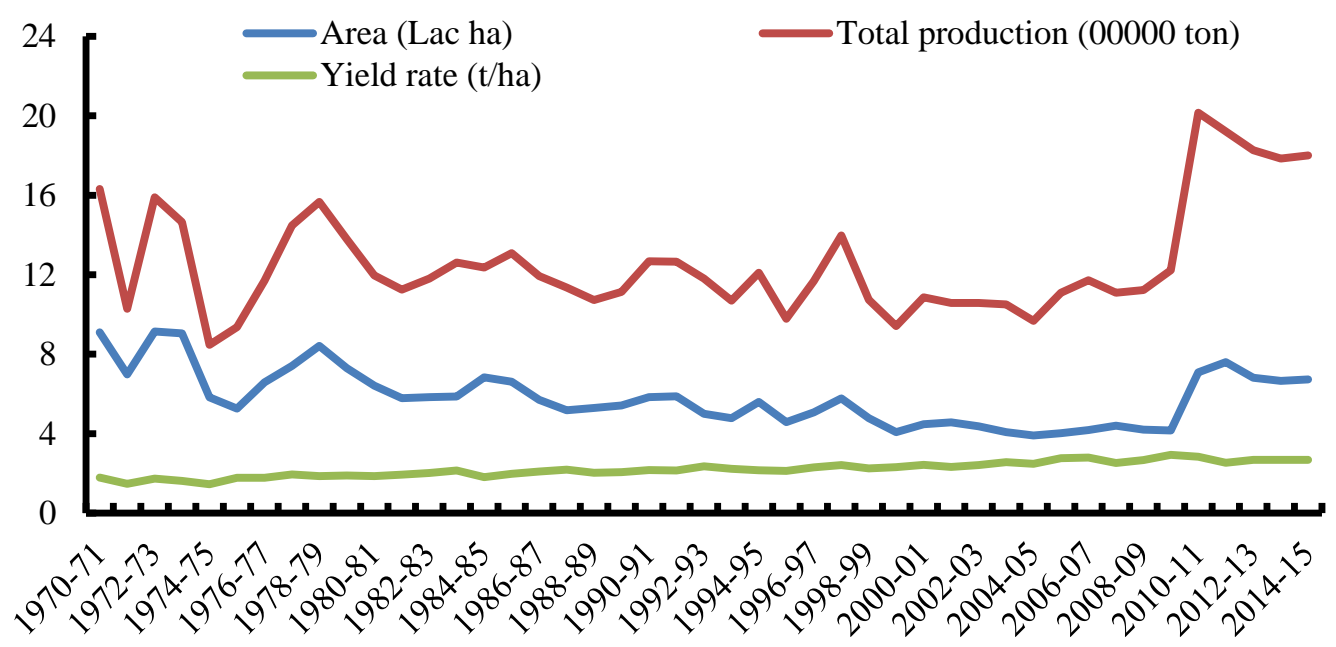

Figure 1 Jute cultivation areas and production trends in Bangladesh (1970-2015) Source: computed from [5].

\section{Material and methods}

An experiment was conducted at the research farm of BINA Sub-station, Gopalganj to screen out the suitable mutant for increasing fiber production. Four mutant lines (JR0-1000-8, JRO-1000-10, JRO-700-3, JR0-1000-9) and two check varieties (JRO-524, BJRI-8) were used in the study. JRO is an abbreviation of Jute Research Olitorius. Four mutants were used for this study which was collected from JRO-524 variety through mutation technique. The experimental design was a randomized completely block with three replications. The area was ploughed using a power tiller. The experimental units separated with a distance of $1.5 \mathrm{~m}$ to ensure that the water does not move from one place to another. The field was divided into three main blocks. Each block was then divided into six plots by using bunds to represent the above mentioned mutants and check varieties. Seeds were sown in $30 \mathrm{~cm}$ between rows. N, P, K, S, Zn fertilizers were applied in the form of urea, TSP, MoP, gypsum and zinc sulfate respectively. Chemical fertilizer was applied at $100 \mathrm{~kg} \mathrm{~N}$ per ha as urea, $39 \mathrm{~kg} \mathrm{P}_{2} \mathrm{O}_{5}$ per ha as triple super phosphates, 30 $\mathrm{kg} \mathrm{K}_{2} \mathrm{O}$ per ha as muriate of potash, $17.14 \mathrm{~kg}$ sulfur per ha as gypsum and $3.70 \mathrm{~kg} \mathrm{Zn}$ per ha as zinc sulfate. Cowdung $5.0 \mathrm{t} \mathrm{ha}^{-1}$ was used in this study. Half of the urea and full dose of other fertilizers were applied at the sowing time. The rest half of urea was top dressed at 45 days after sowing of jute seed. Weeds were manually controlled through occasional hand picking. The crops were attended recommended management practices and harvested at maturity stage. Plant height, base diameter, fiber and stick yield were taken at harvest stage. Plant height was recorded from 10 randomly selected plants from each plot and was taken at harvest. An effective plant height was considered from the ground level to the top of the leaf at harvest stage using the meter scale. The base diameter of plant was measured with a meter scale as the horizontal distance covered by the plant. Data were recorded from ten selected plants at harvest and mean value was counted and was expressed in centimeter. At maturity, an area of 1.0 square meter excluding border rows was taken out in each plot. The fibers of the selected central 1.0 square meter jute mutants and varieties were taken after retting and then their fiber weight was recorded. Their calculated average weight was then expressed in $\mathrm{t} / \mathrm{ha}$. Stick weight was determined from the central 1.0 square meter of each plot. Immediately after harvest of ten plants, the leaves, roots and stems were detached from the plants. The selected plants were cut into small pieces and were kept in an oven at $70{ }^{\circ} \mathrm{C}$ for 72 hours to attain constant weight and the dry weights were recorded and converted into g/plant. Harvest index (HI) was calculated as the ratio of fiber yield to total yield (fiber + 
stick) and multiplied by 100. These data were analyzed statistically by the use of Microsoft Excel computer package program.

\section{Results and discussion}

\subsection{Plant height}

It is proved that the mutant line and the check variety differed significantly with respect to plant height in this study (Figure 2a).The plant height due to different mutants and check varieties ranked in the order of JR0-524> JRO-10008>JRO-1000-10>JRO-1000-9>JRO-700-3>BJRI-8. The tallest plant (3.26 m) was recorded in JR0-524 which followed by the JRO-1000-8, JRO-1000-10, and JRO-1000-9 mutants except JRO-700-3 and BJRI-8. On the other hand, significantly the shortest plant $(2.81 \mathrm{~m})$ was found from the BJRI-8 variety. In general, plant height is the most efficient morphological character which is directly related to greater fiber yield of jute as well as the tallest plant maximizing the fiber yield of jute. Similar findings were also obtained that the statistical analysis showed significant differences among the genotypes for plant height [7]. Results revealed that the performance of different mutants and check varieties exerted pronounced effect on plant height of jute due to genetic makeup.

\subsection{Base diameter}

Statistical analysis data was indicated significant variation due to the effect of different jute mutants and check varieties with the respect of base diameter in this study (Figure 2b). Base diameter is also an important character for fiber yield of jute varieties in case of the higher base diameter produce the better thickness of fiber which will ensure the higher production of fiber. The base diameter due to different mutants and check varieties ranked in the order of JR0-1000-8>JRO-1000-10>BJRI-8>JRO-700-3>JR0-1000-9>JRO-524. Morphological character like base diameter indicated that all the mutant lines achieved maximum performance at harvest stage. Among the jute mutants and check varieties, the highest base diameter $(6.88 \mathrm{~cm})$ was found from the mutant JRO-1000-8 which was followed by JRO-1000-10, BJRI-8, JRO-700-3 and JRO-1000-9 mutant lines. On the other hand, the lowest base diameter $(5.46 \mathrm{~cm})$ was noticed from the JRO-524. The results revealed the performance of different mutants and check varieties exerted pronounced effect on plant height of jute due to genetic makeup. Significant varietal performances on base diameter were also obtained from jute crop $[7,8,9,10]$.

\subsection{Fiber yield}

Results revealed that mutant lines and check varieties differed significantly with respect to fiber yield in this study (Figure 3c). The fiber yield due to different mutants and check varieties ranked in the order of JRO-1000-9>JRO-1000$10>$ JRO-524>JRO-700-3>JRO-1000-8>BJRI-8. Among the mutant lines and check varieties, the highest fiber yield was observed in JRO-1000-9 (3.79 t/ha) which was statistically differed from others. Fiber yield trend indicated that all mutant lines achieved maximum performance at harvest stage except JRO-524 and BJRI-8. These were also found due to its genetic makeup of the present study. Finally, the mutant line JR0-1000-9 had outstanding superiority for fiber yield over other mutants and check varieties in this study.

\subsection{Stick weight}

The effects of mutant lines and check varieties on stick yield results are presented (Figure 4d). The stick yield due to different mutants and check varieties ranked in the order of JRO-524>JRO-100-10>JRO-1000-8>JRO-1000-9>JRO-700$3>$ BJRI-8. JRO-524 produced the highest stick weight ( $8.79 \mathrm{t} / \mathrm{ha}$ ) which was closely related to JRO-1000-10 and JRO$1000-8$. The lowest stick yield (4.73 t/ha) was observed in BJRI-8 which was statistically differed from other mutants and check variety. This variation was found due to its genetic make-up and also the variation of base diameter and plant height. The study was also obtained from jute varieties [11,12] 

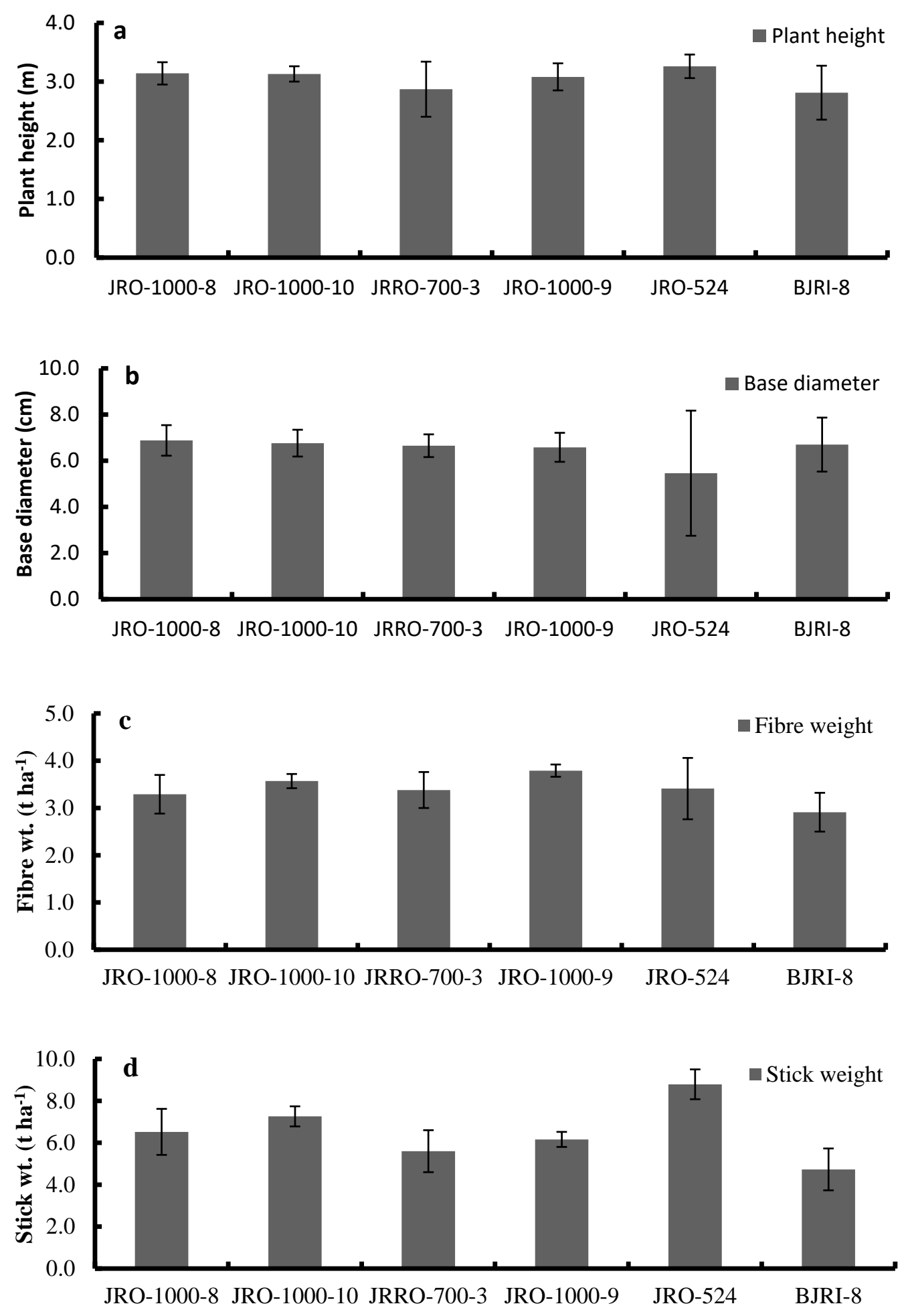

Figure 2 Effect of mutant/variety on yield and yield contributing characters of jute, a : plant height, $\mathrm{b}$ : base diameter, $\mathrm{c}$ : fiber weight and $\mathrm{d}$ : stick weight 


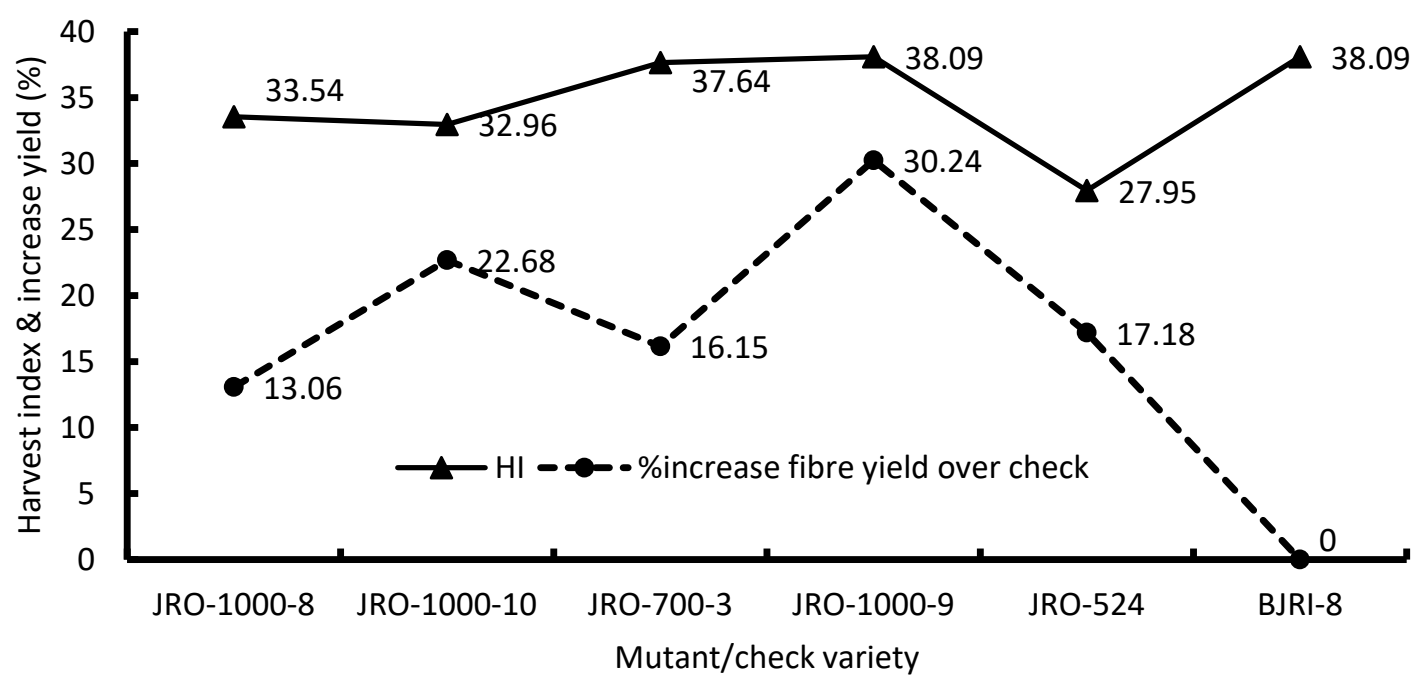

Figure 3 Effect of different mutant/variety on harvest index and \%increase mutant yield over BJRI-8 variety

\subsection{Harvest index and yield increase over check varieties}

The results (harvest index and yield increase over check variety BJRI-8) of this study showed significant variation among the mutants and check variety (Figure 3). Harvest index ranged from 27.95 to $38.09 \%$. The highest harvest index (38.09\%) was obtained from the treatment JRO-1000-9 and BJRI-8. The lowest harvest index (27.95\%) was found in JRO-524 due to higher stick yield. The harvest index obtained from different mutant lines and check varieties ranked in order of JR0-1000-9 = BJRI-8 >JR0-700-3>JRO-1000-8>JRO-1000-10 $>$ JRO-524. Results revealed that BJRI-8 performed the better harvest index but it didn't produce higher fiber yield due to less plant height and the base diameter under this study. JRO-1000-9 mutant produced 30.24\% fiber yield over BJRI-8 check variety. Similar findings were also obtained that the statistical analysis showed significant differences among the genotypes for plant height [13].

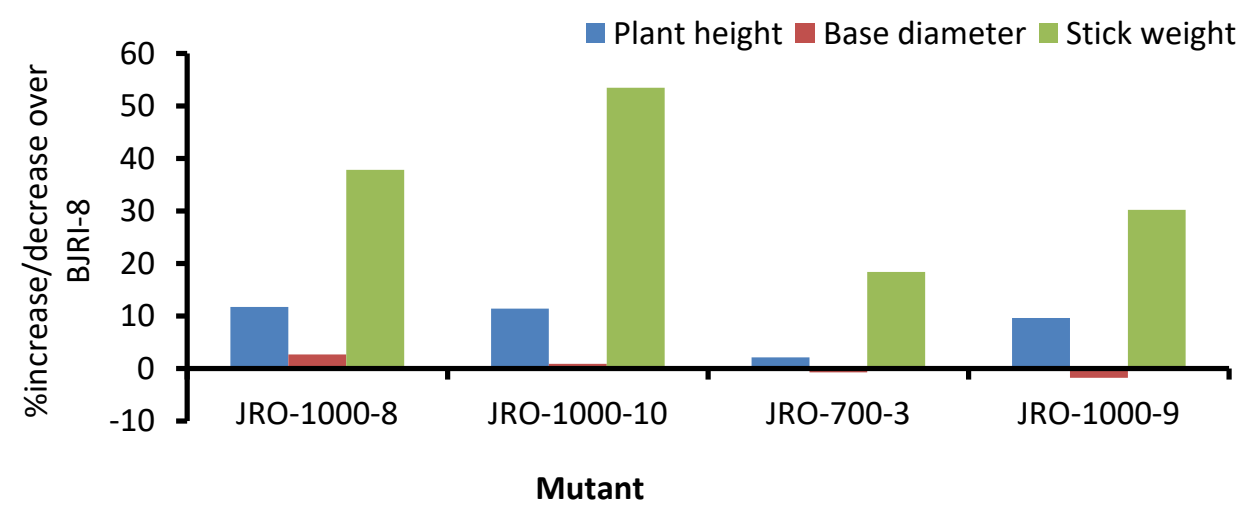

Figure 4 Yield performances on all mutants over BJRI-8 check variety 


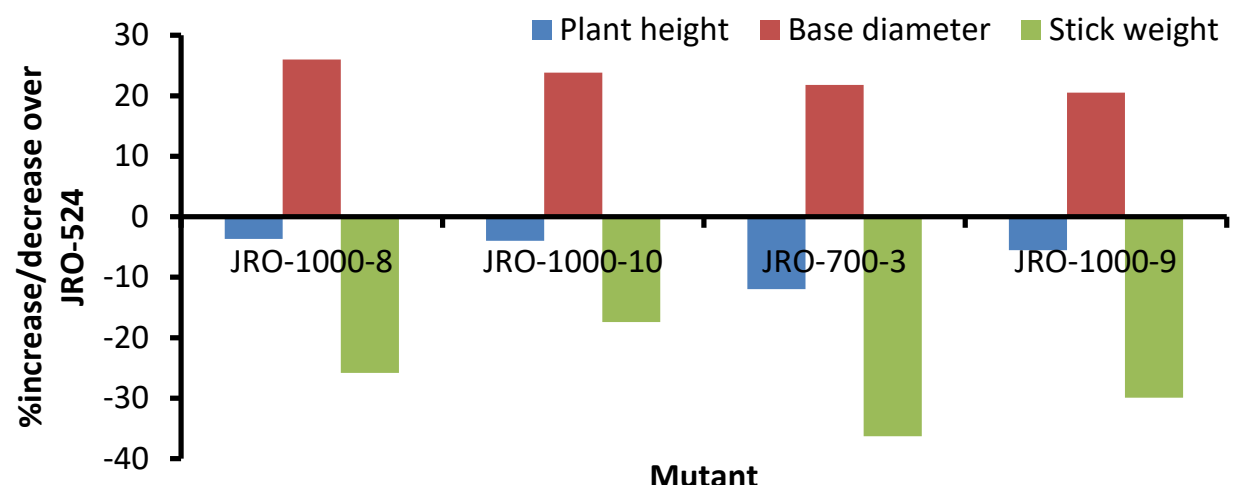

Figure 5 Yield performances on all mutants over JRO-524 check variety

Plant height, base diameter and stick yield results of different mutant lines (JR0-1000-8, JR0-1000-10, JR0-700-3 and JRO-1000-9) performed different degrees over BJRI-8 check variety (Figure 4). In respect of plant height, mutants JRO1000-8, JRO-1000-10, JRO-700-3 and JR0-1000-9 increased 11.74, 11.39, 2.14 and 9.61\% over check variety BJRI-8, respectively. JRO-1000-8 and JRO-1000-10 mutants increased base diameter of jute over check variety BJRI-8. On the contrary, JR0-700-3 and JR0-1000-9 mutants decreased 0.75 and 1.75\% base diameter against check variety BJRI-8, respectively. JRO-1000-8, JR0-1000-10, JRO-700-3 and JRO-1000-9 mutants increased 37.84, 53.49, 18.39 and 30.23\% stick yield over check variety BJRI-8, respectively. Plant height, base diameter and stick yield results of different mutant lines (JR0-1000-8, JRO- 1000-10, JR0-700-3 and JR0-1000-9) performed different degrees over JRO-524 check variety (Figure 5). Mutants JRO-1000-8, JRO-1000-10, JRO-700-3 and JRO-1000-9 decreased 3.68, 3.99, 11.96 and $5.52 \%$ plant height over check variety JRO-524, respectively. In respect of base diameter, mutants JR0-1000-8, JR01000-10, JRO-700-3 and JRO-1000-9 increased 26.01, 23.81, 21.79 and 20.51\% over check variety JRO-524, respectively. JRO-1000-8, JRO-1000-10, JRO-700-3 and JRO-1000-9 decreased stick yield over check variety JRO-524.

Table 1 Correlation coefficient of between fiber and stick yield and morphological characters of jute

\begin{tabular}{lllll}
\hline Parameter & Fiber yield & \multicolumn{3}{c}{ Stick yield } \\
\cline { 2 - 5 } & $\begin{array}{l}\text { Correlation } \\
\text { coefficient }\end{array}$ & Regression equation & $\begin{array}{l}\text { Correlation } \\
\text { coefficient }\end{array}$ & Regression equation \\
\hline Plant height & $0.296^{\mathrm{NS}}$ & $\mathrm{Y}=0.319 \mathrm{x}+1.963$ & $0.849^{* *}$ & $\mathrm{Y}=-0.113 \mathrm{x}+2.310$ \\
Base diameter & $0.010^{\mathrm{NS}}$ & $\mathrm{Y}=-0.179 \mathrm{x}+7.112$ & $0.538^{*}$ & $\mathrm{Y}=-0.272 \mathrm{x}+8.279$ \\
\hline
\end{tabular}

Detailed relationship between the morphological characters (plant height and base diameter) is presented in the Table 1. Fiber yield had no significant relationship with plant height (0.296NS) and base diameter (0.010NS) of jute mutants and check varieties. On the other hand, stick yield had strongly significant positive relationship with plant height $\left(0.849^{* *}\right)$ and base diameter $\left(0.538^{*}\right)$ of jute mutants and check varieties.

\section{Conclusion}

Results of the present study indicated that the most of the mutants showed better performance in respect of fiberstick yield and other morphological characters. It was clearly showed that JRO-1000-9 mutant produced the highest base diameter and fiber yield of jute. Overall results from the present study revealed that JRO-1000-9 was found to be the best mutant for increasing fiber production of jute.

\section{Compliance with ethical standards}

\section{Acknowledgments}

The authors are thankful to the Bangladesh Institute of Nuclear Agriculture (BINA) Sub-station, Gopinathpur, Gopalganj, for providing financial help and logistic support. 


\section{Disclosure of conflict of interest}

The authors declare that they have no conflicts of interest regarding the publication of the article.

\section{Statement of ethical approval}

The authors do certify that the statements made by them are true and correct to the best of their knowledge and belief. They understand that any false statements or any unfair means may provide grounds for the withdrawal or cancellation of the manuscript.

\section{References}

[1] Islam MM. (2009). Jute Seed Technology. 397, Middle Monipur, Mirpur, Dhaka. p. 1.

[2] Saha CK. (2011). Jute seed management in Bangladesh. Procedings, International Seminar on Strengthening of Collaboration for Jute, Kenaf and Allied Fibers Research and Development, 8-9 June, 2011. International Jute Study Group (IJSG), Dhaka, Bangladesh.

[3] Kazal MMH, Rahman S, Alam MJ, Hossain ST. (2013). Financial and economic profitability of selected agricultural crops in Bangladesh. NFPCSP-FAO Research Grant Report \#05/11; Food Planning and Monitoring Unit, Ministry of Food, Government of Bangladesh: Dhaka, Bangladesh.

[4] Basu G and Roy AN. (2008). Blending of jute with different natural fibers. Journal Natural Fibers, 4, 13-29.

[5] BBS (2018). 45 years agriculture statistics of major crops (aus, aman, boro, jute, potato \& wheat). Bangladesh Bureau of Statistics (BBS), Statistics and Information Division (SID), Ministry of Planning, Dhaka, Bangladesh. pp. 127-128.

[6] Khatun R, Sarkar RH and Sobhan MA. (2010). Diallel analysis in seven quantitative traits in deshi jute (Corchorus capsularis L.). Bangladesh Journal of Botany, 39 (2), 137-141.

[7] Pervin N and Haque GKMN. (2012). Path coefficient analysis for fiber yield related traits in deshi jute (Corchorus capsularis L.). International Research Journal Applied Life Science, 1(3), 72-77.

[8] Islam MS, Nasreen A, Begum S and Haque S. (2004). Correlated response and path analysis in Tossa jute (Corchorus olitorius L.). Bangladesh Journal of Botany, 33(2), 99-102.

[9] Islam MM. (2007). Variability and path coefficient analysis in jute (Corchorus olitorius L.) of indigenous origin. Digital Archive on Agricultural Theses and Journal. N Catalog: SAU200701_112. Sher-e-Bangla Agricultural University, Sher-e-Bangla Nagar, Dhaka.

[10] Azad-ud-doula Prodhan AKM, Rahman ML and Haque MA. (2001). Effect of water stresses on growth attributes in jute. II. Plant based diameter. Pakistan Journal of Biological Sciences, 4, 660-664. https://doi.org/10.3923/pjbs.2001.660.664.

[11] Islam MT, Begum MB and Islam MO. (2011). Screening of jute mutants for salinity tolerance. International Journal Sustainable Crop Production, 6(2), 6-11.

[12] Talukder HFA, Sontosh CC, Shahidul IM and Golam SAKM. (2001). Effect of seed filling period on quality of white jute (Corchorus capsularis L.) seed. Journal of Biological Sciences, 1, 365-367.

[13] Khandakar AL. (1985). Screening genotypes for higher harvest index. Ann. Report, pp. 158-165.

\section{How to cite this article}

Akondo MRI, Hossain MB, Rahman MS, Haque MS and Azad MAK. (2020). Screening of suitable tossa jute (Corchorus olitorius L.) mutant to increase fiber production. GSC Biological and Pharmaceutical Sciences, 10(2), 99-105. 